БАРНАШОВ Олег Владимирович - начальник отдела взаимодействия с международными организациями Российского университета дружбы народов (117198, Россия, г. Москва, ул. МиклухоМаклая, 6)

ГЕВОРГЯН Анна Гарнуковна - ассистент кафедры теории и истории международных отношений Российского университета дружбы народов (117198, Россия, г. Москва, ул. Миклухо-Маклая, 6; agevorgyan0101@gmail.com)

ГЕККАЯ Фунда Хайдаровна (Туриия) - аспирант кафедры теории и истории международных отношений Российского университета дружбы народов (117198, Россия, г. Москва, ул. МиклухоМаклая, 6)

\title{
ИЗУЧЕНИЕ МЕЖДУНАРОДНЫХ ОТНОШЕНИЙ В ТУРЦИИ
}

Аннотация. Статья посвящена вопросу изучения международных отношений в Турецкой Республике, процессу формирования основных подходов к анализу международно-политической ситуации. В статье особое внимание уделяется рассмотрению международных отношений как академической дисциплины, развитию основных исследовательских методов анализа данной науки. Авторы анализируют работу научно-исследовательских центров по изучению международных отношений, ведущих государственных и частных вузов, особенности преподавания данной дисциплины и основные области научных исследований ученых-международников.

Ключевые слова: Турция, международные отношения, «мозговые центры» Турции, преподавание международных отношений, ученые-международники, турецкие университеты

И зучение проблем международных отношений и внешней политики приобрело актуальность со второй половины XX в. Особо значимыми для исследователей и практиков, в т.ч. в Турецкой Республике, эти вопросы стали с начала XXI в.

Появление новых проблем, подлежащих исследованию, вызывает к жизни деятельность новых исследовательских центров, использующих в своей работе разнообразные подходы - в зависимости от конкретной исследовательской направленности. Проводя исследование аналитических центров Турции, занимающихся изучением международных отношений, российский ученый В.А. Аватков выделяет некоторые из них, подчеркивая исследовательскую специфику каждого центра. При этом в процессе анализа автор использует хронологический подход [Аватков, Видяйкин 2013: 102-103].

Одним из первых (в 1969 г.) был создан Центр экономических и социальных исследований (Ekonomik ve Sosyal Araștırmalar Merkezi - ESAM)1, ориентированный на разносторонние исследования в области мировой политики, экономики, социальной сферы по запросу правящей Партии справедливости и развития. В 1974 г. был основан Институт внешней политики (Dlș Politika Enstitüsü $-D P E)^{2}$, концентрирующий внимание на проблемах, связанных с Кипром, Европой, Балканами. В проевропейском русле работает и Фонд стратегических и социальных исследований региона Мраморного моря (Marmara Grubu Stratejik ve Sosyal Araștırmalar Vakfi) ${ }^{3}$, созданный в 1985 г. Научно-практический центр международных отношений Университета Мармара (Marmara Üniversitesi Uluslararası İlișkiler Araștırma ve Uygulama Merkezi - MURCIR) 4 с 1994 г. проводит

\footnotetext{
1 http://www.esam.org.tr

2 http://politikakademi.org

3 http://www.marmaragrubu.org

4 https://murcir.marmara.edu.tr
} 
научные исследования по вопросам глобализации, которые в 90-е гг. прошлого века отличались своей значимостью и новизной. Внимание экспертов Центра сосредоточено на балканских, ближневосточных исследованиях, отношениях между Турцией и ЕС, исследовании миграции, на изучении экологической политики и климатических изменений, а также исследованиях активно развивающегося в экономическом плане Азиатско-Тихоокеанского региона.

В интересах Министерства иностранных дел Турции с 1995 г. работает Центр стратегических исследований (Stratejik Araștırmalar Merkezi - SAM) ${ }^{1}$. Учебноисследовательский центр при Министерстве внутренних дел (Araștırma ve Etütler Merkezi - AREM) $)^{2}$ действует с 2000 г. Основное внимание центр уделяет вопросам внутренней политики Турции. В то же время проблемы внутренней политики в исследованиях Центра зачастую представляются в увязке с внешней политикой, главным образом с вопросами миграции. Данный центр - один из примеров функционирования аналитических центров при государственных структурах.

В фокусе внимания Центра стратегического анализа и исследований международных отношений (Uluslararası İlişkiler ve Stratejik Analizler Merkezi TURKSAM) ${ }^{3}$, действующего с 2004 г., находятся проблемы терроризма, миграции, разоружения и отношений Турции со странами ближайшего окружения. Одним из самых крупных на сегодняшний день исследовательских центров Турции является Турецкий центр стратегических исследований Азии (Türk Asya Stratejik Araștırmalar Merkezi - TASAM) ${ }^{4}$. Центр ведет работу с 2003 г., его исследовательская деятельность охватывает весь мир. Действующие в рамках Центра исследовательские группы работают над глобальными проблемами современности - в области экономики, энергетики, охраны окружающей среды и др.

По разным данным, на сегодняшний день на территории Турции действуют от 21 до 90 «мозговых центров». Так, В.А. Аватков и А.С. Видяйкин в своей статье пишут, что, по данным журнала Foreign Affairs, их число составляет 21, в то время как по неофициальным данным в Турции действуют около 50 центров [Аватков, Видяйкин 2013: 101]. Необходимо понимать, что существуют исследовательские центры, действующие при государственных структурах, а также за счет частных фондов. Нужно учитывать и происхождение центров: многие из них, действуя в Турции, имеют западное происхождение и функционируют за счет средств иностранных фондов.

Тем не менее стоит подчеркнуть, что с приходом к власти в Турции Партии справедливости и развития в 2003 г., и особенно с появлением на посту министра иностранных дел Турции Ахмета Давутоглу в 2009 г., число «мозговых центров» в Турции значительно возросло. Это объясняется тем, что новый на то время глава МИДа Турции был не просто государственным чиновником, но являлся еще и крупным ученым в области международных отношений. Придя во власть, он значительно усилил государственную поддержку исследовательских центров, многие из которых в своей работе опирались на его фундаментальный труд по мировой политике и международным отношениям «Стратегическая глубина: международное положение Турции» [Davutoğlu 2011].

На сегодняшний день активное развитие получил Центр политических исследований Анкары (Ankara Politikalar Merkezi - APM) ${ }^{5}$, действующий с 2012 г. Основываясь на теоретических выкладках А. Давутоглу, Центр занимается изу-

\footnotetext{
${ }^{1}$ http://sam.gov.tr/tr/

2 https://www.icisleri.gov.tr/arem

3 https://turksam.org

4 http://www.tasam.org

5 http://www.apm.org
} 
чением вопросов укрепления международного положения Турции, затрагивает проблемы взаимоотношений с приграничными странами и странами дальнего зарубежья, обосновывает географические преимущества Турции в решении политических и экономических проблем. Центр также проводит образовательную деятельность, реализуя программы переподготовки и повышения квалификации в области международной политики, международного права, экономики и обществоведения.

Вопросам безопасности на Ближнем Востоке, а также энергетической и космической безопасности посвящены конференции и симпозиумы, организуемые Центром стратегических исследований при Университете Бейкент (Beykent Üniversitesi Stratejik Araștırmalar Merkezi - BÜSAM) ${ }^{1}$, работающем с 2008 г. В Центре также разрабатываются и реализуются научно-технические проекты, результаты которых используются при разработке направлений стратегической безопасности и в оборонной сфере Турции. В процессе исследований активно используется междисциплинарный подход.

По-своему уникален Центр стратегических исследований мудрецов (Bilge Adamlar Stratejik Araștırmalar Merkezi - BILGESAM)2, созданный в 2008 г. Уникальность Центра состоит в том, что в качестве его экспертов представлены в основном лица, ранее работавшие на государственных должностях и имеющие большой практический опыт в области внутренней и внешней политики. Большая часть работников состоит из отставных и действующих генералов. Основная сфера деятельности Центра - анализ и прогнозы политической ситуации и расстановки сил в мире. Центр также выступает в качестве консалтинговой структуры для органов государственной власти, вырабатывая предложения для принятия государственных решений.

Центр экономических и внешнеполитических исследований (Ekonomi ve Dlş, Politika Araștırma Merkezi - EDAM) ${ }^{3}$ занимается исследованиями в области внешней политики и безопасности, отношений Турции с Европейским союзом, изучением проблем энергетики и окружающей среды, экономики и глобализации, контроля над вооружениями и разоружением, информационной войны. Среди экспертов Центра - представители различных секторов турецкого общества: ученые, представители гражданского общества и бизнес-сообщества, средств массовой информации.

Центр стратегических исследований Южной Азии (Güney Asya Stratejik Araștırmalar Merkezi - GASAM) 4 действует в Стамбуле с 2004 г. Основной сферой деятельности Центра является изучение таких стран, как Пакистан, Афганистан, Индия, Бангладеш, Шри-Ланка, Непал, Бутан, Мальдивские острова. Основное направление исследований - возможность укрепления позиций Турции в регионе Южной Азии. С этой целью проводятся исследования не только геополитической стабильности региона, международно-политических процессов, разворачивающихся там, но и исторического, культурного, этнического, религиозного наследия проживающих в регионе народов. Особое внимание уделено изучению военно-политической обстановки в странах региона, а также социальной активности масс населения.

Центр исследований Черноморского региона (Karadeniz Araștırmaları Merkezi - KaraM $)^{5}$ действует с 2002 г. Центр занимается исследованием северных реги-

\footnotetext{
1 http://iss.beykent.edu.ru

2 http://www.bilgesam.org/ru

3 http://edam.org.tr

4 https://gasam.org.tr/

5 http://www.karam.org.tr/
} 
онов Турции, соприкасающихся с бассейном Черного моря. Как результат, основные направления исследовательской деятельности - это отношения с Балканскими странами, странами Кавказского региона и Восточной Европы. Среди исследуемых проблем основное место занимают вопросы энергетической безопасности, водных ресурсов и окружающей среды.

Ассоциация исследователей Ближнего Востока и Африки (Ortadoğu ve Afrika Araștırmacılar Derneğ $i$ - ORDAF) ${ }^{1}$ - научное объединение исследователей, изучающих международные отношения и культуру стран Ближнего Востока и Африки. В исследованиях членов ассоциации акцент делается на вопросах религии. В том же русле действует и Центр стратегических исследований Ближнего Востока (Ortadoğ u Stratejik Araștırmalar Merkezi - ORSAM) ${ }^{2}$. В свою очередь, Группа стратегических исследований Центральной и Восточной Европы (Orta ve Doğu Avrupa Stratejik Araștırmalar Grubu - ODSTA $)^{3}$ обращает внимание на проблемы Балканского полуострова, а также вопросы европейской интеграции Турции.

В контексте глубоких исследований А. Давутоглу находит место весьма актуальная проблема XXI в. - «мягкая сила» и ее применение во внешней политике [Davutoğlu 2008]. На этой основе в турецких научных кругах сформировалось направление исследования «мягкой силы» во внешней политике Турции, одним из представителей которого является профессор кафедры международных отношений Института социальных наук Университета Сакарья Туба Чавуш. В своем исследовании Чавуш отмечает, что сочетание в Турции исламских порядков и умеренной демократии является самым сильным инструментом и примером «мягкой силы», способной оказать влияние на соседние мусульманские страны, которые желали бы иметь такие же порядки в своих странах [Çavus, 2012: 29]. Сторонники концепции «мягкой силы» в Турции профессора Университета Окан (Стамбул) А.М. Кесеоглу и Г. Чевикел рассматривают «мягкую силу» в применении к практической проблеме гуманитарных операций и сирийских беженцев [Köseoğlu, Çevikel 2014].

K началу XXI в. исследования международных отношений в Турции интенсифицировались, что было связано с появлением проблем глобализации и необходимостью поиска путей их решения на национальном, региональном и общемировом уровне [Аватков 2013]. С приходом к власти в Турции нового правительства во главе с Р.Т. Эрдоганом основной акцент в исследованиях «мозговых центров» Турции был направлен на проблемы международной и региональной безопасности. Основной вопрос, которым продолжают и по сей день заниматься исследователи различных «мозговых центров» Турции, - это место Турции в мировой политике в целом и в отдельных регионах в частности.

Исследованию международных отношений в университетах Турции уделяется значительное внимание. Система высшего образования была внедрена еще в Османской империи начиная со второй половины XIX в., когда в 1859 г. был открыт факультет политологии Анкарского университета (Ankara Üniversitesi) ${ }^{4}$. Чуть позднее, в 1863 г., был открыт Босфорский университет (Boğaziçi Üniversitesi) 5 , который на сегодняшний день является крупнейшим и наиболее авторитетным высшим учебным заведением в Турции. Третий турецкий университет -

\footnotetext{
1 http://ordaf.org

2 http://orsam.org.tr/

3 https://odsta.org/

4 Официальный сайт Анкарского университета. Доступ: http://www.politics.ankara.edu.tr/english/ (проверено 02.02.2019).

5 Официальный сайт Босфорского университета. Доступ: http://www.boun.edu.tr/en_US (проверено 02.02.2019).
} 
Технический университет Йылдыз (Yildiz Teknik Üniversitesi) ${ }^{1}$ был открыт в 1911 г., и, хотя основным направлением его деятельности не являются гуманитарносоциальные науки, в университете действует отделение политологии и международных отношений. Ближневосточный технический университет был открыт в 1956 г., однако факультет международных отношений начал действовать только в 1984 г. На сегодняшний день данное высшее учебное заведение является одним из ведущих в области преподавания международных отношений и политологии. Одним из новейших государственных университетов, в которых имеется кафедра международных отношений, является Университет при Ассоциации образования Турции (Turkish Education Association University - TEDU) ${ }^{2}$, который был открыт в 2009 г. в соответствии с Актом об учреждении $T E D$-университета ${ }^{3}$.

Также преподавание международных отношений осуществляется в ряде частных университетов, подавляющее большинство которых были открыты в конце XX - начале XXI в., в т.ч. Университет Хаджеттепе (Hacettepe Üniversitesi). Также следует отметить такие высшие учебные заведения, как Университет Коч (Кос Üniversitesi), открытый в 1993 г., Стамбульский университет Билги (İstanbul Bilgi Üniversitesi) и Университет Едитепе (Yeditepe Üniversitesi), начавшие деятельность в 1996 г., Международный университет Кипра (Cyprus International University) и Университет Бейкент (Beykent Üniversitesi), которые начали функционировать в 1997 г., Университет Бахчешенир (Bahçeșehir Üniversitesi - BAU), основанный в 1998 г., Университет экономики и технологий при Союзе торговых палат и товарных бирж Турции (TOBB Ekonomi ve Teknoloji Üniversitesi) и Стамбульский университет Айдын (Ístanbul Aydın Üniversitesi), учрежденные в 2003 г., а также городской университет Стамбула (İstanbul Șehir Üniversitesi), открытый в 2008 г.

Ряд высших учебных заведений ведет обучение в области международных отношений как в рамках отдельных программ, действующих на основе отдельных факультетов политологии или международных отношений, так и на кафедрах международных отношений, действующих в рамках факультета экономики и административных наук.

Факультет политологии действует в Анкарском университете, факультет международных отношений существует в университете Бейкент, в Стамбульском университете Айдын действует факультет политологии и международных отношений. Также существует следующий формат преподавания международных отношений: на кафедре международных отношений (в Международном университете Кипра, в Университете Хаджеттепе, в Ближневосточном техническом университете) или на кафедре политологии и международных отношений (в Техническом университете Йылдыз, в $T E D$-университете).

Высшее образование в Турции соответствует европейским стандартам [Tepeciklioğlu 2013: 309] и включает в себя три ступени обучения, в т.ч. бакалавриат, магистратуру и докторантуру $(P h D)$. Обучение ведется на турецком, английском языках. Получение первой степени по программе «Международные отношения» предполагает обучение по следующим дисциплинам ${ }^{4}$ : история Турции, история международных отношений, теория международных отношений, профессиональная ответственность и этика общения, конституционное

\footnotetext{
1 Официальный сайт Технического университета Йылдыз. Доступ: http://www.yildiz.edu.tr/ (проверено 02.02.2019).

2 Официальный сайт Университета при Ассоциации образования Турции. Доступ: https://www.tedu. edu.tr/en/ (проверено 02.02.2019).

3 Акт об учреждении TED-University N 5913 от 23.06.2009. Доступ: https://www.tedu.edu.tr/en/main/ legislation (проверено 02.02.2019).

4 Course Content of Department of International Relations (in Turkish). Доступ: https://www.arel.edu. tr/faculty-of-economics-and-administrative-sciences/department-of-international-relations/course-contents (проверено 02.02.2019).
} 
право, международное право, внешняя политика Турции, проблемы международных отношений, изучение отдельных секторов (по выбору - Европейский союз, Центральная Азия и Кавказ, Ближний Восток и др.). Также в обязательную программу входит изучение турецкого и английского языка (русский, немецкий языки могут изучаться по выбору). С приходом к власти Партии справедливости и развития [Шлыков 2008: 140] также предполагается изучение ислама и его роли в международных отношениях. Поскольку Турция переживает период неоосманизма, пантюркизма, данный процесс сопровождается усилением позиций ислама в стране [Fox, Sandler 2004: 85], что приводит к необходимости изучения роли ислама в международных отношениях в таких ведущих вузах, как Босфорский университет, TED-университет, Стамбульский университет и др.

Одним из наиболее авторитетных высших учебных заведений, в котором имеется кафедра международных отношений, является Анкарский университет, где кафедра дипломатии и международного сотрудничества существовала в период с 1955 по 1982 г., а позднее была переименована в кафедру международных отношений. Кафедра международных отношений включает в себя 3 подразделения, среди которых история дипломатии, международное право и международные отношения. Бакалавриат представляет собой единый учебный курс, основанный на четырехлетнем обучении. Существуют 3 основных магистерских программы, среди которых направления «Международные отношения», а также программа «Международные отношения», не предполагающая написание магистерской диссертации, «Международные отношения в Африканском секторе». Третья степень - докторантура - включает в себя единственное направление - «Международные отношения» и предполагает написание диссертационного исследования по актуальной проблематике и осуществление педагогической практики.

В Босфорском университете имеются иные направления магистратуры, среди которых «Глобализация и международные отношения», «Глобальная политика и международные отношения» с возможностью написания диссертационного исследования или без такового. Программа докторантуры включает в себя одну программу, совмещающую политологию и международные отношения.

Одним из ведущих исследователей в области международных отношений является доктор политических наук профессор Анкарского университета Фунда Кескин Ата (Prof. Dr. Funda Keskin Ata) ${ }^{1}$, которая возглавляет кафедру международных отношений и является автором ряда исследований в области сотрудничества Турции и стран Ближнего Востока 2 , а также трудов, посвященных взаимодействию Турции с Европейским союзом.

Исследованиями в области международных отношений также занимаются Мурат Акан, глава магистерских программ на кафедре политологии и международных отношений Босфорского университета 3 , работы которого посвящены сравнительным аспектам различных геополитических споров, а также имеющимся проблемам международных отношений, Догар Шафак Полат,

1 Официальный сайт Анкарского университета. Доступ: http://www.politics.ankara.edu.tr/english/ (проверено 02.02.2019).

2 Keskin F. Turkey's Trans-Border Operations in Northern Iraq: Before and after the Invasion of Iraq. Research Journal of International Studies. 2008. No. 8. P. 59-75; Suriye Ve Irak İle Su Sorunu F Keskin Çă̆daș Türk Diplomasisi. 1999. 2000 p.; EU-Turkey Relations (1999-2016): Conditionality at Work? - FK Ata Turkish Foreign Policy. 2017. No. 1. P. 105-127; Küresel Uluslararası Örgütler I., - Birleșmiș Milletler Uluslararası Örgütler. No. 4. P. 22-53.

3 Akan M. The Politics of Secularism: Religion, Diversity, and Institutional Change in France and Turkey. Columbia University Press. 2017. 201 p.; Göle Nilüfer. Islam and Secularity: The Future of Europe's Public Sphere. - European Journal of Sociology. 2017. No. 57. P. 501-505; Akan M. 2014. Turkey's Attempt at a New Constitution in Political Context. - Anayasa Hukuku Dergisi (Journal of Constitutional Law). 2014. No. 3(6). 
глава кафедры международных отношений Стамбульского Арельского института1 ${ }^{1}$, а также Есим Арат ${ }^{2}$, Сандаш А., ${ }^{3}$ Мельтем Мюфтюлер-Баш ${ }^{4}$, занимающаяся исследованиями в области турецко-европейских отношений, Зейнеп Кадирбееглу 5 , исследующий внешнеполитическое положение Турции на современном этапе, Волкан Шидан ${ }^{6}$, анализирующий геополитическое положение Турции в ретроспективном аспекте, Хакан Йылмаз ${ }^{7}$, Зейнер Гамбетти ${ }^{8}$, Мехмед Эдер ${ }^{9}$, а также ряд иных исследователей, которые рассматривают различные аспекты международного сотрудничества Турции с иными государствами.

В университетах в дополнение к курсам студентам предоставляется возможность проводить обширные исследования по таким современным проблемам, как отношения с Европейским союзом, политическая экономия, демократизация, права человека, гендерная политика и политика идентичности. Среди преподавательского персонала присутствуют приглашенные профессора из-за рубежа, студентам предлагается большой выбор курсов, что позволяет студентам с начальных курсов специализироваться в конкретных областях международных отношений.

Фундаментальным изучением международных отношений в Турции занимается Дипломатическая академия Министерства иностранных дел.

Она осуществляет программы обучения для профессиональных дипломатов зарубежных стран. Академия также отвечает за планирование и участие сотрудников министерства в учебных программах, языковых курсах и профессиональных семинарах в зарубежных странах. Кроме того, Дипломатическая академия проводит обучение государственных служащих, направляемых в иностранные представительства из других государственных учреждений и организаций ${ }^{10}$.

Таким образом, исследованиями в области международных отношений занимаются ведущие государственные и частные вузы Турции, имеется ряд программ, направленных на освоение знаний в объемах бакалавриата, магистратуры, докторантуры в области международных отношений. Ряд специалистов в области политологии и международных отношений имеют публикации на

\footnotetext{
1 Doğan Şafak Polat Nato ve Rusya Federasyonu'nun yeni mücadele alanı: Karadeniz. Доступ: http:// dspace. marmara.edu.tr/handle $/ 11424 / 207 /$ browse? value $=$ Polat $\% 2 C+$ Do\%C $4 \% 9$ Fan $+\%$ C $5 \% 9$ Eafak\&type $=$ author (проверено 04.02.2019).

2 Yeșim Arat. Islamist Women and Feminist Concerns in Contemporary Turkey Frontiers. - A Journal of Women Studies. 2016. No. 37(3). P. 125-150.

3 Candaș A. Siyasal Rejim Kișiye Özgü Olabilir mi? -Türkiye’nin Anayasa Gündemi (ed. By C. Akaş). İstanbul: İletișim Yayınları. 2016. Pُ. 159-162.

4 Meltem Müftüler-Baç. Turkey's Political Reforms and the Impact of the European Union. - South European Society and Politics. 2005. No. 10(1). P. 16-30; The Era of Dominant-Party Politics. - Keyman Journal of Democracy. 2012. No. 23(1). P. 85-99; Turkish Foreign Policy, Its Domestic Determinants and the Role of the European Union. - South European Society and Politics. No. 16(2). P. 279-291.

5 Paker H., Adaman F., Kadirbeyoğlu Z., Özkaynak B. Environmental Organizations in Turkey. - Engaging the State and Capital Environmental Politics. 2013. No. 22(5). P. 760-778.

6 Çıdam V. Historical Method and Critical Philosophy, Philosophy at Yeditepe, Special Issue. - Method in Philosophy. 2016. P. 231-251.

7 Yilmaz H. et al. The Paradox of Equality. - Subjective Attitudes towards Basic Rights in Turkey. London: Routledge. 2014. P. 330-344.

8 Gambetti Z., Godoy-Anativia M. States of (in) Security: Coming to Terms with an Erratic Terrain. Rhetorics of Insecurity. - Belonging and Violence in the Neoliberal Era. N.Y.: New York University Press. 2013. P. 1-19.

9 Eder M, Özlem Öz. The Making of Transnational Communities: The Case of Shuttle Traders in Laleli, Istanbul. - Transnational Communities and the Regulation of Business. Cambridge: Cambridge University Press. 2010. Р. 82-105.

10 Официальный сайт Дипломатической академии министерства иностранных дел. Доступ: http:// diab.mfa.gov.tr/default.en.mfa (проверено 03.02.2019).
} 
турецком и английском языках, что обеспечивает высокий уровень цитируемости турецких ученых.

Статья подготовлена в рамках НИР РУДН «Незападные теории международных отношений. Азиатские, африканские и латиноамериканские концепции мироустройства».

\title{
Список литературы
}

Аватков В.А. 2013. Внешнеполитическая идеология Туреикой Республики при правлении Партии справедливости и развития: дис. ... к.полит.н. М. 161 с.

Аватков В.А., Видяйкин А.С. 2013. Деятельность аналитических центров в Турции при правлении Партии справедливости и развития. - Вестник МГИМОУниверситета. № 3(30). С. 100-104.

Шлыков П.В. 2008. Эволюция концепции политического ислама в Турции. Турция накануне и после парламентских и президентских выборов 2007 г.: сборник статей. М.: Изд-во ИБВ. С. 115-148.

Çavus T. 2012. Diș politikada yumușak güçk avramı ve türkiye'nin yumușak güç kullanımı - KSÜ İIBFF Dergisi. Vol. 2. Iss. 2. P. 23-36. Доступ: http://iibfdergisi.ksu. edu.tr/download/article-file/107654 (проверено 31.01.2019).

Davutoğlu A. 2008. Turkey's Foreign Policy Vision: An Assessment of 2007. - Insight Turkey. January. Vol. 10. No 1. P. 77-96.

Davutoğlu A. 2011. Stratejik Derinlik. Türkiyenin uluslararası konumu. İstanbul. 584 s.

Fox J., Sandler Sh. 2004. Bringing Religion into International Relations. N.Y.: Palgrave Macmillan. 213 p.

Köseoğlu A.M., Çevikel G. 2014. Yumușak güç: insani yardım operasyonları ve Türkiye'deki suriyeli mülteciler. - Akademik Bakıș Dergisi. Mayıs-Haziran. № 43. Доступ: http://dergipark.gov.tr/download/article-file/382848 (проверено 31.01.2019).

Tepeciklioğlu E.E. 2013. Türkiye’de Uluslararası İlișkiler Eğitimi: Lisans ve Lisansüstü Ders Programlarının Karșılaștırmalı Bir Analizi. - Ege Akademik Bakıș. No. 3. S. 303-316.

BARNASHOV Oleg Vladimirovich, Head of the Department of Cooperation with International Organizations, Peoples' Friendship University of Russia (6 Miklukho-Maklaya St, Moscow, Russia, 117198)

GEVORGYAN Anna Garnugovna, Assistant at the Department of Theory and History of International Relations, Peoples' Friendship University of Russia (6 Miklukho-Maklaya St, Moscow, Russia, 117198)

GEKKAYA Funda (Turkey), postgraduate student at the Department of Theory and History of International Relations, Peoples' Friendship University of Russia (6 Miklukho-Maklaya St, Moscow, Russia, 117198)

\section{STUDY OF INTERNATIONAL RELATIONS IN TURKEY}

\begin{abstract}
The article is devoted to an issue of the study of international relations in the Republic of Turkey, to the process of formation of the main approaches of the analysis of an international and political situation. The article focuses on the consideration of the international relations as academic discipline, the development of the main research methods of the analysis in this science. The authors consider research centers of studying the international relations, leading state and private universities, the features of teaching and the main fields of scientific research of foreign affairs specialists.

Keywords: Turkey, international relations, Turkish think tanks, teaching in international relations, foreign affairs specialists, Turkish universities
\end{abstract}

